\title{
Is it really brand love? A cautionary note on Nguyen and Feng's study
}

\author{
Author: Salim Moussa \\ ORCID : 0000-0003-2589-0719
}

\begin{abstract}
Correspondence address: Institut Supérieur des Études Appliquées en Humanités, Cité des Jeunes, Gafsa 2133, Tunisie
\end{abstract}

Phone number: +21676226161 ;

E-mail:salimmoussa@yahoo.fr

\section{Acknowledgment}

The author wants to thank Professor Hui Feng for sending him the final version of the article she co-authored with Hang T. Nguyen.

\section{Declaration of conflicting interests}

The author declares no potential conflicts of interest regarding this research note. The author however would like to indicate that this manuscript stemmed from a letter he sent (on 17 April 2021) to P.K. Kannan, the ongoing editor-in-chief of the International Journal of Research in Marketing, the publication venue of the article by Nguyen and Feng. Receiving no reply to his letter, the author officially forwarded (on 20 April 2021) a manuscript framed as a commentary to that journal. On the $3^{\text {rd }}$ of May 2021, the editor-in-chief of the

International Journal of Research in Marketing desk-rejected the author's manuscript. In his decision letter, P.K. Kannan wrote: "I read through your paper carefully and appreciate your comments on the brand love paper by Nguyen and Feng. Interesting as it may be, this piece does not qualify for full length article and we do not publish comments as a note".

\section{Author biography}

Salim Moussa is an Assistant Professor in Marketing at the Higher Institute of Applied Studies in Humanities, University of Gafsa, Tunisia. He holds a Ph.D. in Management Sciences with a focus on marketing from the University of Tunis, Tunisia. His current research interests include consumer psychology of brands, marketing journals, and marketing analytics. Salim has hitherto published in such publication outlets as the International Journal of Market Research, Journal of Brand Management, Journal of Consumer Behaviour, Marketing Intelligence \& Planning, International Journal of Consumer Studies, Journal of Marketing Analytics, Applied Marketing Analytics, Journal of Informetrics, Scientometrics, The Journal of Academic Librarianship, and Aslib Journal of Information Management. 


\title{
Is it really brand love? A cautionary note on Nguyen and Feng's study
}

\begin{abstract}
In this cautionary note, the author argues that the recent study by Nguyen and Feng (https://doi.org/10.1016/j.ijresmar.2020.10.001) did not investigate the antecedents and financial impacts of building brand love but rather those of brand liking. A close examination of some of the descriptive statistics reported by Nguyen and Feng indicates that their statistical models were run on consumer responses that are more indicative of brand liking than brand love. The author also demonstrates via one correlation estimate and one coefficient alpha value (taken from Nguyen and Feng's article) that the single-item measure these authors used to gauge brand love is less than reliable. Marketing scholars, market researchers and brand managers are advised to be extremely cautious concerning the theoretical and managerial implications of that study.
\end{abstract}

Keywords: brand love; brand liking; critique; measurement; reliability; validity 
There's a widespread belief in our business that consumers are in love with brands. That consumers want to have brand experiences and brand relationships and be personally engaged with brands and read branded story telling [...] People have shaky jobs and unstable families, they have illnesses, they have debts, they have washing machines that don't work, they have funny things growing on their backs, they have kids that are unhappy, they have a lot of things to care deeply about. It's very unwise to believe that they care deeply about our batteries, our wet wipes and our chicken strips.

—Bob Hoffman, former owner and CEO of the advertising agency Hoffman/Lewis

\section{Introduction}

Brand love has become central to modern marketing theory and practice (Batra, Ahuvia, \& Bagozzi, 2012; Benmiloud, 2017; Carroll \& Ahuvia, 2006; Moussa, 2019a, 2019b; Schreane, 2020). Numerous are those advertising/branding/market research agencies (like Accenture Interactive/Fjord, BERA Brand Management, Drumroll, Harris Interactive, NetBase and

Oath) that are presently proposing love scores, indices and rankings for brands. Overabundant are those scholarly articles that have investigated brand love's nature, causes, and consequences (for a recent systematic review of the brand love literature, see Gumparthi \& Patra, 2020). A basic search on Clarivate Analytics' Web of Science (performed on 12 May 2021) shows that 212 articles with the expression "brand love" in their titles have appeared since 2006 in over a hundred journals indexed in the Web of Science Core Collection. To put it briefly, brand love is in vogue both in academia and practice (Moussa, 2019c).

For some cynics, "brand love is oversold" (Clark, 2020). Within the extant literature, brand love is often fervently forwarded as "the most emotionally intense connection between consumers and their brands" (Schmid \& Huber, 2019, p.305), "an intrinsically interesting topic" (Bagozzi, Batra, \& Ahuvia, 2017, p.1), and as a construct "of great importance to academics and practitioners" (Gumparthi \& Patra, 2020, p.93). Brand love, a few enthusiastic commentators assert, "is universal" and we "need to think about 'love' not within a specific product category but across the entire universe of brands" (Barker, Peacock, \& Fetscherin, 2015, p. 669). 
Rhetoric and other literary devices aside, recent reviews of the brand love literature indicate that extant studies suffer from three deficiencies: (a) the positioning of "the brand love concept as a rather static phenomenon" (Palusuk, Koles, \& Hasan, 2019, p.106) (b) the lack "of empirical support for the return on brand love" (Moussa, 2019c, p.154); and (c) "the extensive use of students as respondents" (Gumparthi \& Patra, 2020, p.121).

A study that sets itself apart from the rest is the one by Nguyen and Feng (forthcoming). That recent study warrants particular attention because it: (a) is a longitudinal study that covers 12 years (from 2006 to 2017); (b) shows that "brand love" in time t has significant positive effects on firm performance (as measured in terms of Return on Assets, Return on Equity, and Market Capitalisation) in times $t+2$ and $t+3$ (but not in $t+1$ ); and (c) uses over 20,000 consumer responses collected by the market research agency Harris Interactive. Hence, at first sight, the study by Nguyen and Feng seems to address the three aforesaid deficiencies in brand love research.

Recent critical reviews of the brand love literature also indicate that extant studies are not only characterised by "difficulties [in] distinguishing brand love from other proximal constructs such as brand liking" (Palusuk et al., 2019, p.98) but also "are full of methodological flaws and far-fetched findings" (Moussa, 2019c, p.148).

In this cautionary note, the author argues that the recent study by Nguyen and Feng did not investigate the antecedents and financial impacts of building brand love but rather those of brand liking. To support his argument, the author uses some descriptive statistics, one correlation estimate and one coefficient alpha value that could be found in Nguyen and Feng's article.

Nguyen and Feng are to be commended for providing an article replete with details. In Nguyen and Feng's article, many are the tables (eight tables), the appendices (two tables), and 
the web appendices (seven tables). Without all these details, this cautionary note would not be written.

The profusion of details in Nguyen and Feng's article permits to any reader with critical eyes to come up with the following conclusion: Nguyen and Feng's study suffers from three significant shortcomings. These three shortcomings are enumerated and discussed below.

\section{Is it brand love or brand liking?}

First, any careful reader of Nguyen and Feng's article would quickly come to realise that the statistical models in that study were run on consumer responses that could not, by any means, associated with brand love. In their study, Nguyen and Feng have used a dataset collected by the market research agency Harris Interactive. As part of its poll, Harris Interactive gauges "brand love" using a five-point single-item measure (hereinafter SIM) with the following points: 1 = "you hate the brand", 2 = "you dislike the brand", 3 = "you do not have any strong feelings about the brand", $4=$ "you like the brand", and $5=$ "you love the brand". When a respondent gives a brand a 3 , he/she is not in love with that brand. It is only when a respondent chooses the fifth response category on that SIM that one may talk about brand love. In Harris Interactive's SIM, brand love corresponds to one particular point (i.e., the fifth and final point). The problem — at least for the moment — is not with Harris Interactive's SIM of "brand love" but rather with the way the data collected using such a SIM has been analysed.

In their article, Nguyen and Feng state the following:

For each brand, the brand love score is the weighted average of more than 2,000 consumer responses on a yearly basis [...] We use Harris Interactive's brand love scores in our model as it is a panel dataset across many industries and years. 
Nguyen and Feng (forthcoming) report a weighted average "brand love" rating of 3.13 (out of a maximum score of 5). This average rating of +.13 above the neutral midpoint of 3 is visibly more indicative of "not having any strong feelings about the brand" than brand love. Nguyen and Feng also report a standard deviation (STD) of 1.40 for the average "brand love" rating. In addition, Nguyen and Feng mention that they have confirmed the normality of the distribution of their data using Jarque-Bera test. Since consumers' responses on the SIM of brand love follow a normal distribution, an interval covered by one standard deviation above and below the mean (i.e., Mean \pm 1 STD) includes about $68 \%$ of the responses. This rule is known in statistics as the 68-95-99.7 rule or the three-sigma rule (see Grafarend, 2006, p.553). As Figure 1 suggests, the statistical models in Nguyen and Feng were run on responses that most of which (i.e., more than 2/3) are comprised between 1.73 and 4.53. This interval includes brand disliking (i.e., response category 2) and brand liking (i.e., response category 4). It does not include brand loving (i.e., response category 5). Based on these descriptive statistics, it is safe to state that Nguyen and Feng have investigated the antecedents and financial impacts of brand liking rather than those of brand love (see Figure 1).

\section{$\underline{\text { Insert Figure } 1 \text { about here }}$}

Unfortunately, Nguyen and Feng provide neither in their paper nor in its numerous web appendices further information about the distribution of the responses to the SIM of brand love. For instance, it would be interesting to know how many of the over 20,000 consumer responses fall under category 5= "love the brand". Given that consumer responses on the SIM of brand love are normally distributed and applying the three-sigma rule, that number would be about $[20,000 \times(1-.68)] / 2=3,200$ responses; that is, $16 \%$ of the 20,000 consumer responses. 
For the sake of information, the SIM used by Harris Interactive is almost identical to the one developed by Rossiter (2012, p.911), which is also a five-point SIM with "Hate", "Dislike", "Neutral", "Liking", and "Love" as the five answer categories. But unlike Nguyen and Feng, Rossiter (2012) did not use his SIM to calculate a brand love score. Rossiter (2012, pp.912913) rather provides percentages of brand lovers for each product category and each brand.

\section{Is Harris Interactive's single-item measure of brand love reliable?}

Second, Nguyen and Feng do not report any reliability estimate for Harris Interactive's SIM. To prove the face validity of that SIM, they provide a correlation estimate between the 2017 score on that SIM and the score obtained from a multi-item measure (MIM) of brand love (i.e., eight items seven of which are from Carroll \& Ahuvia, 2006, p.84) administrated to 700 respondents as part of a 2017 survey. The correlation estimate between the SIM and the MIM of brand love (in 2017) is equal to $\mathrm{r}_{\mathrm{SIM} / \mathrm{MIM}}=.72(p<.001)$. The internal consistency reliability of that MIM, as Nguyen and Feng indicate, is $\alpha=.89$.

The reliability of Harris Interactive's SIM could be straightforwardly estimated using procedures advocated by Wanous and colleagues (Wanous \& Hudy, 2001; Wanous, Reichers, \& Hudy, 1997). Wanous and colleagues showed how the formula for correction of attenuation in Nunnally and Bernstein (1994, p.257) can be used to estimate the reliability of a SIM. Assuming that the correlation between two error-free measures of the same construct is 1 , the correlation between the two measures (i.e., the SIM and the MIM) and the internal consistency reliability (e.g., coefficient $\alpha$ ) for the MIM, which can both be estimated from the data, can be plugged into the formula for correction of attenuation, which leaves the reliability for the SIM as the only unknown in the formula. Rearranging the formula makes it possible to solve for the SIM reliability. 
The formula for correction of attenuation is: $r_{A B}=r_{x y} / \sqrt{S_{x} S_{y}}$, where $r_{A B}$ is the corrected correlation between the two constructs $\mathrm{A}$ and $\mathrm{B}, \mathrm{r}_{\mathrm{xy}}$ is the observed correlation between measure $\mathrm{x}$ (taping A) and $\mathrm{y}(\operatorname{taping} \mathrm{B})$, and $\mathrm{S}_{\mathrm{x}}$ and $\mathrm{S}_{\mathrm{y}}$ are their respective reliabilities. Assuming that $\mathrm{A}$ and $\mathrm{B}$ are the same construct (i.e., brand love), that measures $\mathrm{x}$ and $\mathrm{y}$ are taping that same construct (i.e., brand love), and that $r_{A B}$ is equal to 1 , then $S_{y}=r_{x y}^{2} / S_{x}$. This approach to the assessment of the reliability of SIMs is well-known in psychometrics (see e.g., Zijlmans et al., 2018a, 2018b). Bergkvist (2015) adopted that same approach for assessing the reliability of the SIMs used in the study by Bergkvist and Rossiter (2007).

With an internal consistency of $\alpha=.89$ for the MIM and a correlation of .72 between the SIM and MIM, the application of Wanous and colleagues' approach yielded a reliability of .58 for Harris Interactive's SIM. Such a value is less than satisfactory according to accepted standards for SIMs (i.e., a minimum of .70 according to Wanous et al., 1997, p.250).

\section{What is brand love and how Nguyen and Feng measured it?}

Third, though Nguyen and Feng have adopted Carroll and Ahuvia's (2006) conceptualisation of brand love, the MIM they used excludes a central component of that very conceptualisation, namely emotional attachment.

For Carroll and Ahuvia (2006, p.81), brand love is "the degree of passionate emotional attachment a satisfied consumer has for a particular trade name". According to these authors, brand love "includes passion for the brand, attachment to the brand, positive evaluation of the brand, positive emotions in response to the brand, and declarations of love for the brand" (Carroll \& Ahuvia, 2006, p.81, emphasis added). Emotional attachment is also one of the key 14 factors/components of brand love as conceptualised by Batra et al. (2012, p.8) and Bagozzi et al. (2017, p.3). 
Table 1 presents Carroll and Ahuvia's (2006) brand love scale in its original version along with the version used by Nguyen and Feng (forthcoming). As Table 1 shows, in addition to excluding the two reverse-coded items (i.e., item 4 and item 7), the MIM of brand love used by Nguyen and Feng excludes item 10 (i.e., "I'm very attached to this brand") in Carroll and Ahuvia (2006). Table 1 also shows that Nguyen and Feng have added the item "This brand gives me a pleasure". The author's queries here are as follows: Why excluding item 10? Isn't attachment a defining component of brand love? Is pleasure a more relevant component to brand love than attachment?

\section{$\underline{\text { Insert Table } 1 \text { about here }}$}

\section{Conclusion}

Some brand love researchers are still making the same major mistakes: First, they cannot differentiate brand love from its close constructs (Moussa, 2015; Rossiter, 2012). Second, they are inappropriately using less than reliable measurement instruments to gauge brand love (Moussa, 2019c).

Nguyen and Feng's study is one of the many studies that confuse brand love with brand liking. It also inadequately uses a non-reliable SIM in which brand love corresponds to the ultimate point in a continuum, not the continuum itself. The study by Nguyen and Feng does not demonstrate the return for getting to that ultimate point (Clark, 2020). Even the MIM used by Nguyen and Feng to confirm the face validity of the employed SIM is a questionable version of Carroll and Ahuvia's (2006) original brand love scale. Given these fatal flaws, marketing scholars, market researchers and brand managers are advised to be extremely cautious concerning the theoretical and managerial implications enumerated in Nguyen and Feng's article. 
To conclude, the author wholeheartedly hopes that the points raised in this cautionary note could be helpful for the advancement of the theory and practice of brand love.

\section{References}

Bagozzi, R. P., Batra, R., \& Ahuvia, A. (2017). Brand love: development and validation of a practical scale. Marketing Letters, 28(1), 1-14.

Barker, R., Peacock, J., \& Fetscherin, M. (2015). The power of brand love. International Journal of Market Research, 57(5), 669-672.

Batra, R., Ahuvia, A., \& Bagozzi, R. P. (2012). Brand love. Journal of Marketing, 76(2), 116.

Benmiloud, J. (2017). Why be liked when you can be loved?. Journal of Brand Strategy, 6(1), $14-25$.

Bergkvist, L. (2015). Appropriate use of single-item measures is here to stay. Marketing Letters, 26(3), 245-255.

Bergkvist, L., \& Rossiter, J. R. (2007). The predictive validity of multiple-item versus singleitem measures of the same constructs. Journal of Marketing Research, 44(2), 175-184.

Carroll, B. A., \& Ahuvia, A. C. (2006). Some antecedents and outcomes of brand love. Marketing Letters, 17(2), 79-89.

Clark, B. (2020, November 1). Brand love is oversold [blog post]. Retrieved from https://bruceclarkprof.medium.com/brand-love-is-oversold-ae1cc18feb2f 
Grafarend, E. W. (2006). Linear and nonlinear models: fixed effects, random effects, and mixed models. de Gruyter.

Gumparthi, V. P., \& Patra, S. (2020). The phenomenon of brand love: a systematic literature review. Journal of Relationship Marketing, 19(2), 93-132.

Moussa, S. (2015). I may be a twin but I'm one of a kind: Are brand attachment and brand love different names for the same construct? Qualitative Market Research, 18(1), 69-85.

Moussa, S. (2019a). Is this love that I'm feelin'?. International Journal of Market Research, 61(6), 574-576.

Moussa, S. (2019b). I'm in love with the bobo. International Journal of Market Research, 61(6), 581-584.

Moussa, S. (2019c). If it is love, can I get my money back? A critical review of the brand love literature. The Marketing Review, 19(3-4), 147-159.

Nguyen, H. T., \& Feng, H. (forthcoming). Antecedents and financial impacts of building brand love. International Journal of Research in Marketing. https://doi.org/10.1016/j.ijresmar.2020.10.001

Nunnally, J. C., \& Bernstein, I. H. (1994). Psychometric theory (3rd ed.), McGraw-Hill, New York, NY.

Palusuk, N., Koles, B., \& Hasan, R. (2019). 'All you need is brand love': a critical review and comprehensive conceptual framework for brand love. Journal of Marketing Management, 35(1-2), 97-129.

Rossiter, J. R. (2012). A new C-OAR-SE-based content-valid and predictively valid measure that distinguishes brand love from brand liking. Marketing Letters, 23(3), 905-916. 
Schmid, D. A., \& Huber, F. (2019). Brand love: Emotionality and development of its elements across the relationship lifecycle. Psychology \& Marketing, 36(4), 305-320.

Schreane, T. (2020). Creating a culture of brand love. Marketing News, Retrieved from https://www.ama.org/marketing-news/creating-a-culture-of-brand-love/

Wanous, J. P., \& Hudy, M. J. (2001). Single-item reliability: a replication and extension. Organizational Research Methods, 4(4), 361-375.

Wanous, J. P., Reichers, A. E., \& Hudy, M. J. (1997). Overall job satisfaction: how good are single-item measures?. Journal of Applied Psychology, 82(2), 247-252.

Zijlmans, E. A., van der Ark, L. A., Tijmstra, J., \& Sijtsma, K. (2018a). Methods for estimating item-score reliability. Applied Psychological Measurement, 42(7), 553-570.

Zijlmans, E. A., Tijmstra, J., van der Ark, L. A., \& Sijtsma, K. (2018b). Item-score reliability in empirical-data sets and its relationship with other item indices. Educational and Psychological Measurement, 78(6), 998-1020. 
Table 1. Original and adapted versions of Carroll and Ahuvia's brand love scale

\begin{tabular}{|c|c|}
\hline $\begin{array}{c}\text { Carroll and Ahuvia's brand love scale } \\
\text { (original version) }\end{array}$ & $\begin{array}{l}\text { Carroll and Ahuvia's brand love scale } \\
\text { (version used be Nguyen and Feng) }\end{array}$ \\
\hline 1. This is a wonderful brand. & 1. This is a wonderful brand. \\
\hline 2. This brand makes me feel good. & 2. This brand makes me feel good. \\
\hline 3. This brand is totally awesome. & 3. This brand gives me a pleasure. \\
\hline 4. I have neutral feelings about this brand. (-) & 4. This brand is totally awesome. \\
\hline 5. This brand makes me very happy. & 5. This brand makes me very happy. \\
\hline 6. I love this brand! & 6. I love this brand! \\
\hline $\begin{array}{l}\text { 7. I have no particular feelings about this brand. } \\
\text { (-) }\end{array}$ & 7. I am passionate about this brand. \\
\hline $\begin{array}{l}\text { 8. This brand is a pure delight. } \\
\text { 9. I am passionate about this brand. }\end{array}$ & 8. This brand is a pure delight. \\
\hline 10. I'm very attached to this brand. & \\
\hline
\end{tabular}

$$
\text { Cronbach's } \alpha=.91 \quad \text { Cronbach's } \alpha=.89
$$

\footnotetext{
Note: Italicized items were either excluded from or added to the original version of Carroll and Ahuvia's (2006) brand love scale.
} 


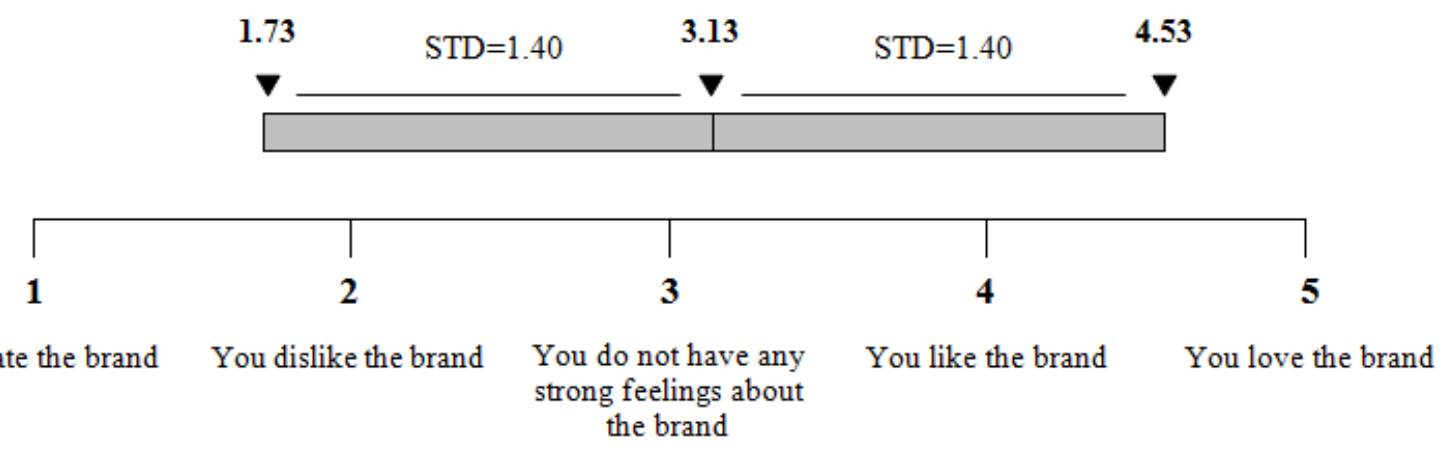

Figure 1. Descriptive statistics of responses distribution on Harris Interactive's single-item measure of brand love 